\section{Persepsi Peserta Program PS PPI Unilla Mengenai Aplikasi Pembelajaran Daring}

\author{
Ika Kustiani, Dikpride Despa
}

Dosen senior Fakultas Teknik, Homebase di Program Studi Program Pendidikan Profesi Insinyur, Universitas Lampung

psppi@unila.ac.id

\section{Pendahuluan}

Penggunaan gelar Insinyur (Ir) sebagai gelar akademik yang diberikan kepada orang yang telah selesai menempuh pendidikan Sarjana dalam bidang teknik tidak lagi digunakan sejak tahun 1994 dan diganti dengan gelar S.T. (Sarjana Teknik). Akan tetapi, saat ini melalui Undang-Undang Nomor 11 Tahun 2014 tentang Keinsinyuran Pemerintah kembali membuka gelar Insinyur melalui kegiatan yang disebut dengan Program Profesi Insinyur (PPI). PPI adalah program pendidikan tinggi setelah program sarjana untuk membentuk kompetensi Keinsinyuran. Jadi jika dulu gelar Insinyur itu adalah gelar akademik sekarang menjadi gelar profesi. Gelar insinyur itu kembali digunakan karena sejumlah alasan, antara lain merupakan upaya untuk meningkatkan jumlah dan mutu insinyur profesional agar setara dengan negara dengan teknologi maju sehingga siap berkarya secara global serta untuk penyeragaman gelar di bidang keahlian teknik dan pertanian.

Mengacu pada Permen Nomor 35 Tahun 2016 Tentang Program Profesi Insinyur Pasal 4, terdapat dua jalur program yaitu regular dan RPL (Rekognisi Pembelajaran Lampau). Saat ini, Program Studi Program Pendidikan Profesi Insinyur Universitas Lampung baru menawarkan program RPL. Di mana Pasal 5 menjelaskan bahwa program RPL merupakan cara penyetaraan atau pengakuan capaian pembelajaran seseorang dengan kualifikasi akademik sarjana bidang teknik atau sarjana terapan bidang teknik dan memiliki pengalaman kerja lebih dari 5 (lima) tahun.

Dengan asumsi bahwa mayoritas calon peserta RPL adalah profesional aktif, ini menciptakan kendala tersendiri ketika ingin mendaftar ke PPI. Sebagai solusi,
Program Studi Program Pendidikan Insinyur Universitas Lampung (PS PPI Unila) saat ini hanya menawarkan program Rekognisi Pembelajaran Lampau (RPL). Peserta Program RPL merupakan profesional yang masih aktif berkarir. Untuk peserta program sepert ini pembelajaran daring menawarkan kemudahan dan fleksibilitas serta efisiensi. Studi ini menyajikan persepsi peserta program PS PPI Unila terhadap wacana pengembangan sistem pembelajaran daring PS PPI Unila. Metode pengabilan data dilakukan melalui kuisioner dan analisis data dilakukan dengan bantuan program Statistical Program for Social Sciences (SPSS). Hasil analisis menunjukkan dukungan dan persepsi yang positif terhadap wacana pengembangan pembelajaran daring untuk PS PPI Unila.

Kata kunci : RPL, PSPPI, Pembelajaran Daring

Dlpresentasikan: 30 Agustus 2019

Direvisi: 14 September 2019

Diterima: 2 Oktober 2019

Dipublikasikan online: 5 Oktober 2019

sistem pembelajaran daring kini menjadi salah satu alternatif untuk memudahkan siapa saja yang ingin menjadi peserta PPI. Salah satu kelebihan dari kuliah dengan sistem pembelajaran daring adalah pembelajaran dilakukan dari jarak jauh. Peseta PPI tidak selalu perlu datang ke kelas dan bertatap muka langsung dengan dosen dengan memanfaatkan fasilitas teknologi digital dan koneksi internet. Selain itu, peserta juga dapat mengakses bahan ajar di mana saja dan kapan saja tanpa terkendala jarak.

Di Universitas Lampung, terdapat dua sistem pembelajaran daring yang dapat dimanfaatkan yaitu SPADA (Sistem Pembelajaran Daring) dan VC (Virtual Class). Tulisan ini memaparkan sistem pembelajaran daring yang sedang dikembangkan oleh PS PPI Universitas Lampung (PS PPI Unila) dan persepsi peserta program terhadap sistem pembelajaran daring melalui virtual class Universitas Lampung.

\section{Metode}

Justifikasi mengembangkan aplikasi pembelajaran daring untuk PS PPI Universitas Lampung adalah berdasarkan kajian data dan informasi mengenai kelebihan sistem pembelajaran daring serta persepsi calon pengguna sistem tersebut. Adapun metode pengumpuluan informasi diambil melalui sumber primer dan sekunder. Informasi primer. Pada studi ini sumber primer berupa survei persepsi melalui kuisioner yang ditanyakan kepada peserta program PS PPI Unila. Sedangkan informasi sekunder berupa kajian pustaka mengenai sistem pembelajaran daring dan virtual class. Metode analisis data menggunakan program Statistical Program for Social Sciences (SPSS). Selanjutnya hasil analisis disajikan secara deskriptif pada subbab selanjutnya.

Cara mensitasi artikel ini:

Kustiani, I., Despa, D (2019) Persepsi Peserta Program PS PPI Unila Mengenai Aplikasi Pembelajaran Daring. [Edisi Khusus]. Buletin Profesi Insinyur 2(3): 122-124 


\section{Hasil dan Analisis}

Sistem Pembelajaran Daring dan Kelas Virtual Unila Sistem pembelajaran daring merupakan wujud implementasi dari pendidikan jarak jauh oleh perguruan tinggi untuk meningkatkan kualitas pembelajaran. Materi pembelajaran dapat disesuaikan dengan kurikulum dan elemen-elemen program studi. Selain itu, tujuan dan manfaat materi pembelajaran dapat dibuat dengan lebih mudah dan menarik sehingga dapat dipahami dengan lebih baik. Sistem pembelajaran daring yang sedang dikembangkan oleh PS PPI Unila adalah kelas virtual (Virtual Class Unila: https://vclass.unila.ac.id/). Kelas virtual adalah lingkungan belajar online yang memungkinkan interaksi/komunikasi/partisipasi langsung antara tutor dan peserta atau antar peserta program dalam kegiatan pembelajaran. Alat paling umum yang digunakan di kelas virtual adalah: presentasi, konferensi video dan papan tulis online untuk kolaborasi waktu nyata (Firdaus, 2019).

\section{Persepsi pengguna aplikasi pembelajaran daring}

Svendsen dan Small (1990) menyatakan bahwa survei persepsi melalui kuesioner cocok untuk menilai kinerja suatu system. Abernethy, dkk (2001) menjelaskan aspek yang perlu dipertimbangkan dalam melakukan survei persepsi seperti teknik/metodologi, jenis kuesioner, dan analisis temuan. Diadaptasi dari Abernethy, Jinapala, dan Makin (Abernethy, dkk, 2001), survei persepsi dari pihak pengguna suatu sistem berguna untuk mengidentifikasi dan menilai manfaat penting dari penerapan aplikasi pembelajaran daring untuk PS PPI Unila.

Dalam penelitian ini, metode kuantitatif digunakan karena mudah dan cepat, andal dan mudah. Seperangkat pertanyaan diajukan untuk mendapatkan wawasan dan pendapat tentang dampak/manfaat spesifik penerapan aplikasi pembelajaran daring pada PS PPI Unila. Kuesioner dirancang dalam bahasa lokal (Bahasa Indonesia) dan sesingkat mungkin (terdiri dari 10 pertanyaan). Baik pertanyaan tertutup dan pertanyaan terbuka digunakan dalam survei dan dibagi menjadi dua bagian. Bagian A terdiri dari pertanyaan umum untuk mengidentifikasi profil responden dan Bagian B dimaksudkan untuk mendapatkan pandangan dan pendapat dari para responden. Hasil survei kuesioner dianalisis secara statistik menggunakan program SPSS.

Survei persepsi dilaksanakan pada tanggal 20 Agustus 2019. Responden berjumlah 32 orang, merupakan peserta baru program PS PPI Unila yang hadir pada saat kuliah perdana program PS PPI Unila.

Seluruh responden menyatakan belum pernah mendengar informasi mengenai sistem pembelajaran daring dan belum pernah mengakses laman sitem pembelajaran daring Unila. Mayoritas (87\%) terkendala waktu, jarak atau keduanya untuk bias dating setiap saat ke kampus Unila. Mayoritas responden mengatakan bahwa aplikasi pembelajaran daring PS PPI Unila memberikan dampak yang positif terhadap kendala waktu dan jarak. Mayoritas responden setuju bahwa karakteristik sistem pembelajaran daring seperti presentasi power point, video, dan konferensi video dan papan tulis online yang digunakan dalam aplikasi pembelajaran daring PS PPI Unila memberikan dampak yang positif terhadap kemudahan pemahaman materi. Mayoritas responden juga mengatakan fleksibilitas dalam mengakses materi pembelajaran daring kapan saja dan dimana saja membuat calon peserta program tertarik untuk mendaftar.

\section{Kesimpulan}

Pada kondisi dimana peserta didik terkendala oleh waktu dan jarak, kuliah dengan sistem pembelajaran daring dapat membantu peserta untuk mengakses PS PPI dengan mudah dan efisien. Materi digital pembelajaran jarak jauh memungkinkan peserta program mengakses berbagai materi dan mengunduh dalam bentuk buku elektronik. Materi pembelajaran dapat disesuaikan dengan kebutuhan dan dibuat dengan menarik sehingga dapat dipahami dengan lebih baik. Terlebih lagi, proses belajar dan jadwal akses yang fleksibel tentunya akan sangat membantu peserta program yang umumnya merupakan profesional yang masih aktif berkarir.

\section{Ucapan Terimakasih}

Terima kasih kepada PS PPI Universitas Lampung atas dukungan finansial dalam penulisan dan presentasi makalah ini.

\section{Referensi}

Svendsen, M., Small, L. E. (1990) Farmer's perspective on irrigation performance, Irrigation and Drainage Systems 4: 385-402.

Abernethy, C. L., Jinapala, K., Makin, I, W., (2001) Assessing the opinions of users of water projects, Irrigation and Drainage 50(3) (2001): p 173-193.

Firdaus, R (2019) Pembelajaran Inovatif Berbasis Teknologi Informasi. 


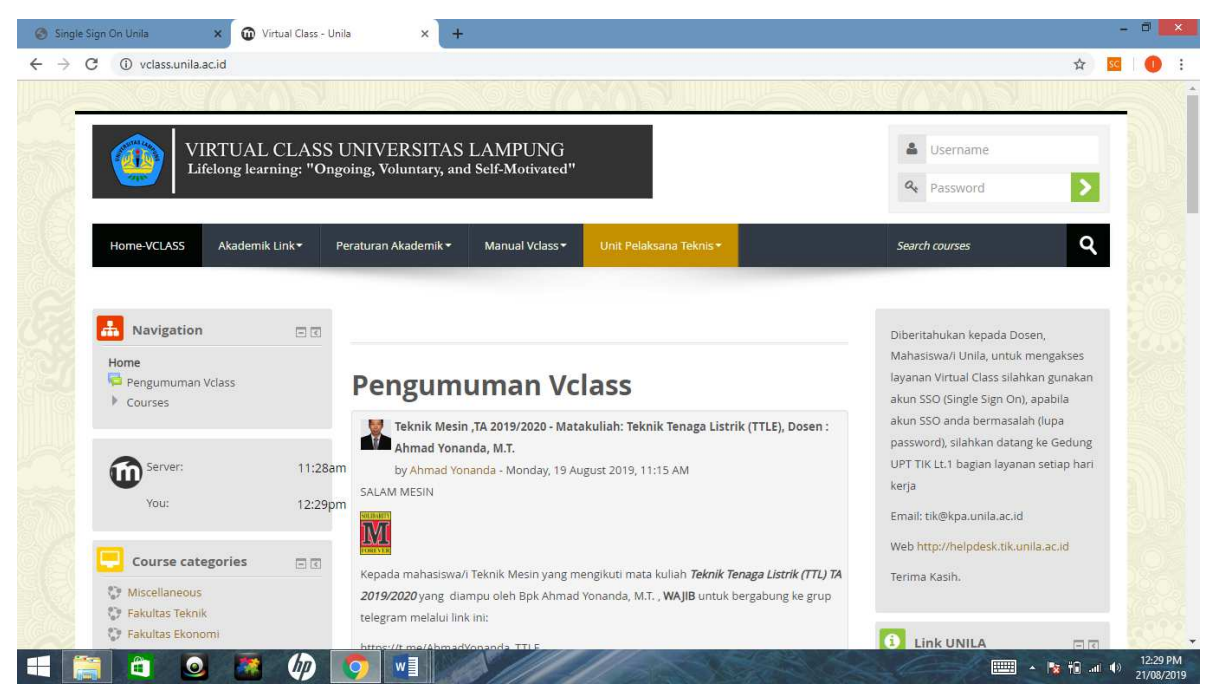

Gambar 1. Tampilan Virtual Class Unila 